\title{
Ellipsis
}

2021

\section{Intimacy Coaching}

Josie Oliva

Follow this and additional works at: https://scholarworks.uno.edu/ellipsis

\section{Recommended Citation}

Oliva, Josie (2021) "Intimacy Coaching," Ellipsis: Vol. 46 , Article 26.

DOI: https://doi.org/10.46428/ejail.46.26

Available at: https://scholarworks.uno.edu/ellipsis/vol46/iss1/26

This Essay is brought to you for free and open access by the Department of English and Foreign Languages at ScholarWorks@UNO. It has been accepted for inclusion in Ellipsis by an authorized editor of ScholarWorks@UNO. For more information, please contact scholarworks@uno.edu. 


\section{Intimacy Coaching by Josie Oliva}

Suck it up and straddle him. In retrospect, it's quite a comical phrase, but I was certainly daunted by such instruction while mustering up the courage to kiss someone whom, at that time, I hardly knew. I was given this order by a dear friend and mentor of mine while choreographing an intimate scene, and it became somewhat of our catchphrase for the remainder of our play. As an experienced actor and director herself, Brittany always had a devious plan for pushing me out of my comfort zone, even if it meant taunting me with absurdly suggestive comments.

When I first heard about auditions for a local theatre's production of Bonnie and Clyde the Musical, I was excited to finally be presented with an opportunity to build my acting résumé. I auditioned for the lead role (along with several other women), not at all expecting to even be considered for the part. I simply wanted to showcase my talents for the future reference of the board of directors. I was ecstatic when I received the cast list after a grueling week of anticipation, but I didn't know exactly what I had gotten myself into until I researched my role. Bonnie and Clyde the Musical: complete with an extensive number of stage kisses and a hot-andheavy sex scene. I was open to the challenge of embodying such a mature character as Bonnie Parker, but I was not prepared to meet my director's expectations. Though we had never worked with each other before, my co-lead and I were given free rein on the blocking of our intimate scenes, but what good does that do when neither of us is comfortable staging these interactions? There were many times when we would be deep into a scene or song and disrupt our rhythm by breaking character to skirt the stage directions. Needless to say, our director lost patience with our stalling. We were becoming frustrated ourselves, but no matter how hard we tried, we simply couldn't manage the kiss. It wasn't until I was approached by my mentor, Brittany Bourque, who had been trained in intimacy coaching, that we began to block the scenes. I had never heard of this type of directing, but through a series of private workshops, we finally staged our intimate scenes in a manner that was comfortable for both me and my partner. I think we even surprised the rest of the cast when we began incorporating the blocking into rehearsals, as they hadn't yet seen us progress past our initial awkwardness. With Brittany's meticulous instruction, my colead and I were able to develop our characters through interactions that looked and felt natural. Considering our substantial progress, I'm led to wonder why the presence of an intimacy coach was not established from the beginning of rehearsals. For the sake of realistic and ethical performances, I believe intimacy directors should be deemed a necessary part of the production team when the performance involves intimate interactions.

Intimacy coaching, itself, was spurred from the use of violence in film and theatre. Fight director David Brimmer stated that violence is a part of human nature, and therefore exhibiting aggression on stage must be made to look realistic (Dominus). Considering the need for realism, it is the responsibility of the fight choreographer to stage the combat in a manner that protects the actors involved. Likewise, an intimacy coach must direct the actors through the safest means of contact, a process which begins by first establishing boundaries. These boundaries are the foundation of the choreography and are necessary for creating a scene that looks natural. For my co-lead and I, Brittany introduced Extreme Stage Physicality (ESP), a technique developed by 
fight director Adam Noble. Noble's technique begins by having the actors engage in simple, nonsensual contact i.e. holding hands or sitting just close enough that the knees touch. This establishes a physical connection that allows the actors to feel comfortable with each other without the pressure of performing the actual choreography. Then, the actors and coach will discuss where and how they are comfortable with being touched. For instance, I'm ticklish, so during this step, I let my partner know what things would trigger that reaction. Once all boundaries are set, the coach and actors may begin choreographing, usually by start-stop pacing to ensure the safety and well-being of the actors. For personal touch, Noble also incorporated a mini-guide to stage violence into ESP, which to some coaches proves just as useful as intimacy techniques.

Not only are intimacy directors requested to mediate physicality, they are also called on to offer emotional support to actors. Years after Noble's techniques were established, Tonia Sina and her associates, Siobhan Richardson and Alicia Rodis, founded Intimacy Directors International. Spurred by their own intimacy horror stories, the women created the Pillars program, establishing it as "the core protocol of IDI" (Purcell). Context, communication, consent, and choreography were the original four pillars of the program and aimed to provide a guide for directing physical contact. The recently added fifth pillar, closure, was set to provide actors and directors with a debriefing after each rehearsal of an intimate scene or other potentially traumatizing role. According to the Intimacy Directors website, IDI enhances directors' skills in movement and body but also certifies them in fields such as "consent, sexual harassment, ... [and] mental health first aid." Co-founder Alicia Rodis explained that directors are not therapists or counselors, but they know what resources to provide when someone is having a mental crisis (Purcell). Further, closure was named a pillar in order to help actors reconcile themselves with the mindset of their characters, especially when the role is emotionally or mentally taxing. This allows actors to "walk away" from a role and proves that winding down after a performance is just as important as getting into character (Purcell).

The accessibility of resources like ESP and Pillars begs the question of why it has taken so long for intimacy directors to be incorporated as necessary elements of production teams. As job opportunities for properly trained crew members open, researchers point to the recent outbreak of sexual harassment allegations in the film, television, and theatre industries. It is believed that the \#MeToo movement in Hollywood has spurred an awareness in actors and directors alike, leading to an increase in jobs for certified intimacy coaches. As for why these jobs have only now become available, directors and producers may argue that hiring such coaches is an unnecessary cost. This also correlates with the industry's “do-it-yourself" ideology, the belief that intimacy should and can be handled by the actors involved. Considering the nature of the allegations, perhaps effective mediation is overlooked when it comes to intimate interactions on camera and on stage. Rather, actors are given vague, unproductive, and potentially harmful instructions on how to maneuver contact-heavy scenes, thus increasing the chances of sexual harassment and injury. Sources, such as Actor CEO, recognize that directors "may think that implementing structure around intimate scenes will squelch the actor's creative impulse," but, on the contrary, creativity is heightened when intimacy protocols like ESP and Pillars are applied (Zien). By the guidance of intimacy coaches, actors may be further immersed in an environment which cultivates authenticity and integrity in performance. 
As an actress myself, it's undoubtedly uncomfortable and sometimes embarrassing to stop in the middle of a scene to confirm a partner's consent; but awkward as it may be, it's an imperative step in the developmental process. With the appropriate supervision, the choreography and chemistry may flourish into a performance that is exquisitely fluid and organic. This is why I too would like to be certified in stage intimacy. I want to share my experiences with actors who, like me, may need someone to break down an intimate scene. I want to build the vision of the body and voice in ways that are expressive of natural emotion. With the entertainment industry becoming increasingly explicit, there is a promising demand for intimacy directors, and I hope to contribute to the performing community by means of producing truthful and magnificent art.

\section{Works Cited}

Dominus, Susan. "Not Just a Fight Director, but a Fight-to-the-Death Director." The New York Times, The New York Times, 20 Feb. 2005, www.nytimes.com/2005/02/20/theater /newsandfeatures/not-just-a-fight-director-but-a-fighttothedeath-director.html.

Purcell, Carey. "Intimate Exchanges." AMERICAN THEATRE, 24 Oct. 2018, www.americantheatre.org/2018/10/23/intimate-exchanges/.

Zien, Carly. "\#MeToo and Acting: Why Intimacy Coaching Is Essential." Actor CEO, 17 Apr. 2019, actorceo.com/metoo-and-acting-why-intimacy-coaching-is-essential/ 